\title{
Artificial modification of an enzyme for construction of cross-reactive polyion complexes to fingerprint signatures of proteins and mammalian cells
}

\author{
Shunsuke Tomita ${ }^{* a}$, Osamu Niwa ${ }^{\text {a,b }}$, and Ryoji Kurita ${ }^{* a}$
}

a Biomedical Research Institute, National Institute of Advanced Industrial Science and Technology, and

DAILAB, 1-1-1 Higashi, Tsukuba, Ibaraki 305-8566, Japan

${ }^{\mathrm{b}}$ Advanced Science Research Laboratory, Saitama Institute of Technology, 1690 Fusaiji, Fukaya, Saitama 369-0293, Japan

E-mail: s.tomita@aist.go.jp; r.kurita@aist.go.jp 


\section{Table of contents}

Table S-1. Properties of 16 anionic enzymes and the extent of maximum inhibition by cationic polymers.

Table S-2. Classification accuracy of cross-reactive enzyme-based sensors for discrimination of six plasma proteins.

Figure S-1. Profiles of biological analytes used in this study.

Figure S-2. $\quad$ Far-UV CD spectra of unmodified $\beta$-Gal (E1) mixed with hydrolyzed acetic anhydride (AA), hexanoic anhydride (HA), benzoic anhydride (BA), succinic anhydride (SA) and phthalic anhydride (PA).

Figure S-3. Kinetic experiments of unmodified $\beta$-Gal mixed with hydrolyzed acid hydrides.

Figure S-4. Preparation and characterization of $\beta$-Gals modified with various acid anhydrides.

Figure S-5. Lineweaver-Burk plots for substrate hydrolysis by E1 - E6.

Figure S-6. Residual activities of artificially modified $\beta$-Gals after shaking treatment at $2000 \mathrm{rpm}$ for 30 minutes at room temperature.

Figure S-7. Schematic representation of the process for exploring the best combination of PICs based on the Jackknife classification procedure.

Figure S-8. First discriminant scores vs. $\mathrm{p} I$ and $\Phi_{\text {surface }}$ values of plasma proteins.

Figure S-9. Fingerprints of changes in enzyme activity for different concentrations of inflammatory biomarker proteins, mammalian sera and cells.

Figure S-10. Discriminant score plots for four types of biological samples analyzed using six PICs

Figure S-11. Normalized activities of artificially modified $\beta$-Gals in the presence of P2, and fingerprints of changes in enzyme activity for different concentrations of inflammatory biomarker proteins in $10 \mathrm{mM}$ MOPS ( $\mathrm{pH} 7.0)$ with $1 \%$ human serum

\section{References}


Table S-1. Properties of 16 anionic enzymes and the extent of maximum inhibition by cationic polymers. Only five enzymes were strongly inhibited.

\begin{tabular}{llccc}
\hline Anionic enzyme & Source & $\mathrm{pI}$ & $\mathrm{Mw}(\mathrm{kDa})$ & Inhibition $^{{ }^{\mathrm{a}}}$ \\
\hline$\beta$-Galactosidase & Aspergillus oryzae & 5.2 & 110 & $* * *$ \\
& Escherichia coli & 5.1 & 465 & $* * *$ \\
& Bovine liver & 6.7 & 71 & $*$ \\
$\alpha$-Amylase & Aspergillus oryzae & 4.2 & 52 & $* * *$ \\
Cellulase & Porcine pancreas & 6.4 & 55 & $*$ \\
$\alpha$-Glucosidase & Aspergillus niger & 4.1 & 24 & $* *$ \\
$\beta$-Glucuronidase & Saccharomyces cerevisiae & 5.5 & 68 & $*$ \\
& Bovine liver & 5.1 & 290 & $* *$ \\
Amyloglucosidase & Escherichia coli & 5.3 & 274 & $*$ \\
Lipase & Aspergillus niger & 4.2 & 66 & $* * *$ \\
& Aspergillus niger & 4.0 & 32 & $* * *$ \\
& Pseudomonas fluorescencs & 5.6 & 33 & $*$ \\
Alkaline phosphatase & Escherichia coli & 4.7 & 57 & $* *$ \\
Esterase & Pseudomonas fluorescens & 5.5 & 50 & $*$ \\
\hline
\end{tabular}

${ }^{\text {a }}$ Enzyme activity was decreased to $* 60-100 \%$, **30-60\% and $* * * 0-30 \%$ in the presence of cationic polymers.

Table S-2. Classification accuracy of cross-reactive enzyme-based sensors for discrimination of six plasma proteins.

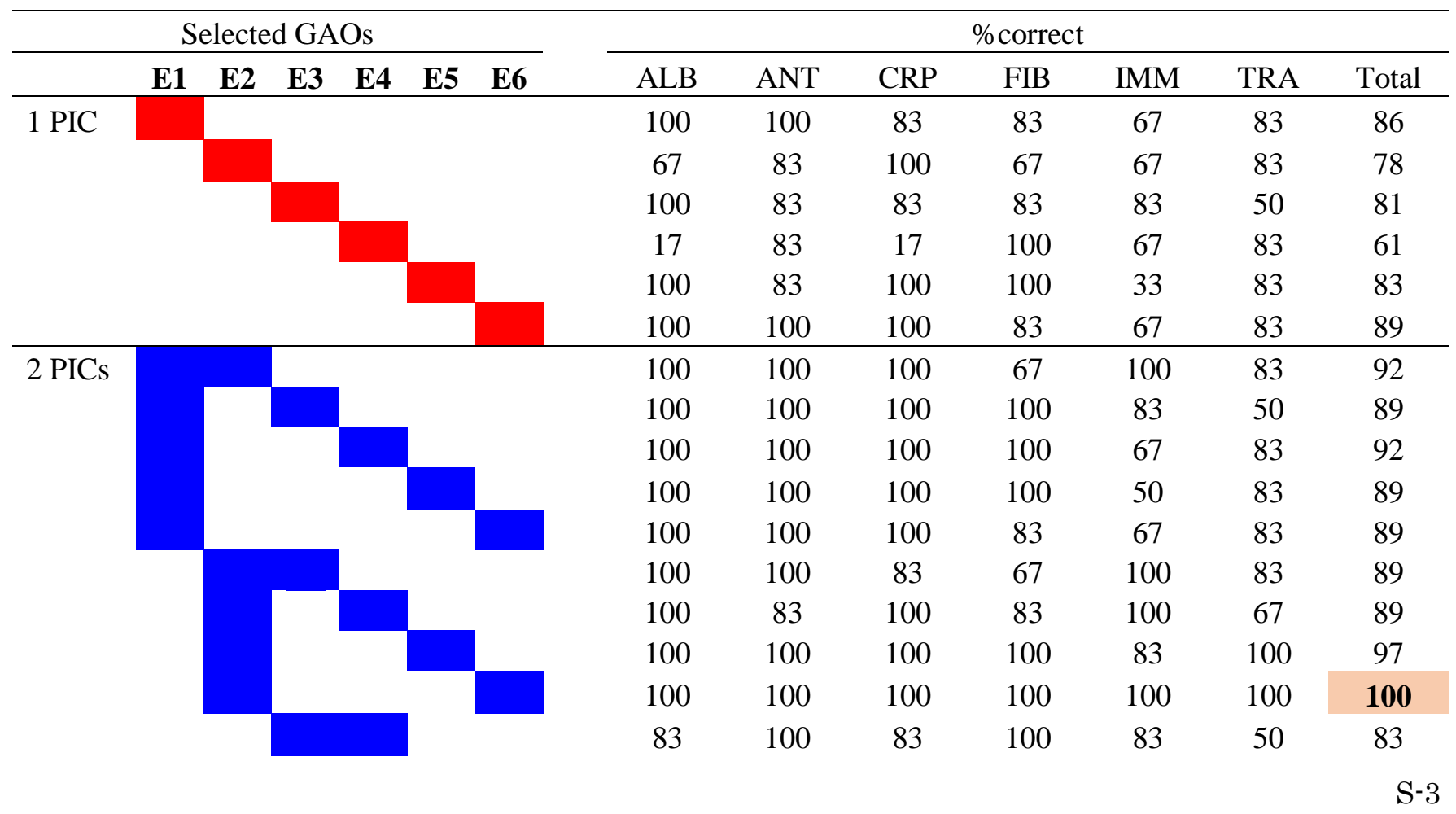




\begin{tabular}{|c|c|c|c|c|c|c|c|}
\hline & 100 & 83 & 83 & 100 & 67 & 67 & 83 \\
\hline & 100 & 100 & 83 & 83 & 83 & 83 & 89 \\
\hline & 67 & 83 & 100 & 100 & 33 & 83 & 78 \\
\hline & 100 & 100 & 100 & 83 & 67 & 83 & 89 \\
\hline & 100 & 100 & 100 & 100 & 67 & 83 & 92 \\
\hline 3 PICs & 100 & 100 & 100 & 83 & 100 & 83 & 94 \\
\hline & 100 & 100 & 100 & 67 & 100 & 67 & 89 \\
\hline & 100 & 100 & 100 & 100 & 83 & 100 & 97 \\
\hline & 100 & 100 & 100 & 100 & 100 & 100 & 100 \\
\hline & 100 & 100 & 100 & 100 & 83 & 50 & 89 \\
\hline & 100 & 100 & 100 & 100 & 67 & 67 & 89 \\
\hline & 100 & 100 & 100 & 100 & 83 & 83 & 94 \\
\hline & 100 & 100 & 100 & 100 & 50 & 83 & 89 \\
\hline & 100 & 100 & 100 & 83 & 67 & 83 & 89 \\
\hline & 100 & 100 & 100 & 100 & 67 & 83 & 92 \\
\hline & 100 & 100 & 83 & 83 & 100 & 83 & 92 \\
\hline & 100 & 100 & 100 & 100 & 100 & 100 & 100 \\
\hline & 100 & 100 & 100 & 100 & 100 & 100 & 100 \\
\hline & 100 & 100 & 100 & 100 & 83 & 100 & 97 \\
\hline & 100 & 100 & 100 & 100 & 100 & 100 & 100 \\
\hline & 100 & 100 & 100 & 100 & 83 & 100 & 97 \\
\hline & 100 & 83 & 83 & 100 & 83 & 67 & 86 \\
\hline & 100 & 100 & 83 & 83 & 83 & 83 & 89 \\
\hline & 100 & 100 & 83 & 100 & 67 & 83 & 89 \\
\hline 4 PICs & 100 & 100 & 100 & 100 & 100 & 83 & 97 \\
\hline & 100 & 100 & 100 & 100 & 100 & 100 & 100 \\
\hline & 100 & 100 & 100 & 100 & 100 & 100 & 100 \\
\hline & 100 & 100 & 100 & 100 & 83 & 100 & 97 \\
\hline & 100 & 100 & 100 & 100 & 100 & 100 & 100 \\
\hline & 100 & 100 & 100 & 100 & 83 & 100 & 97 \\
\hline & 100 & 100 & 100 & 100 & 67 & 67 & 89 \\
\hline & 100 & 100 & 100 & 100 & 83 & 83 & 94 \\
\hline & 100 & 100 & 100 & 100 & 67 & 83 & 92 \\
\hline & 100 & 100 & 100 & 100 & 67 & 83 & 92 \\
\hline & 100 & 100 & 100 & 100 & 100 & 100 & 100 \\
\hline & 100 & 100 & 100 & 100 & 100 & 83 & 97 \\
\hline & 100 & 100 & 100 & 100 & 83 & 100 & 97 \\
\hline & 100 & 100 & 100 & 100 & 83 & 100 & 97 \\
\hline & 100 & 100 & 83 & 100 & 67 & 83 & 89 \\
\hline 5 PICs & 100 & 100 & 100 & 100 & 100 & 100 & 100 \\
\hline & 100 & 100 & 100 & 100 & 100 & 83 & 97 \\
\hline & 100 & 100 & 100 & 100 & 83 & 100 & 97 \\
\hline & 100 & 100 & 100 & 100 & 83 & 100 & 97 \\
\hline & 100 & 100 & 100 & 100 & 83 & 83 & 94 \\
\hline & 100 & 100 & 100 & 100 & 83 & 100 & 97 \\
\hline 6 PICs & 100 & 100 & 100 & 100 & 83 & 100 & 97 \\
\hline
\end{tabular}




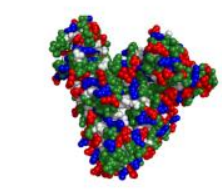

Albumin (ALB)

$\mathrm{Mw}=67 \mathrm{kDa}$

$\mathrm{p} /=5.7$

$\Phi_{\text {surace }}=0.275$

PDB entry: 1E78

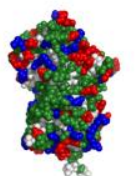

$\alpha_{1}$-Antitrypsin (ANT)

$\mathrm{Mw}=44 \mathrm{kDa}$

$\mathrm{p} /=5.4$

$\Phi_{\text {surface }}=0.263$

PDB entry: $1 \mathrm{HP} 7$

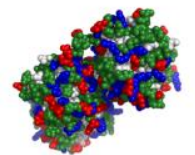

Transferrin (TRA)

$\mathrm{Mw}=75 \mathrm{kDa}$

$\mathrm{p} /=6.7$

$\Phi_{\text {surace }}=0.246$

PDB entry: $3 Q Y$
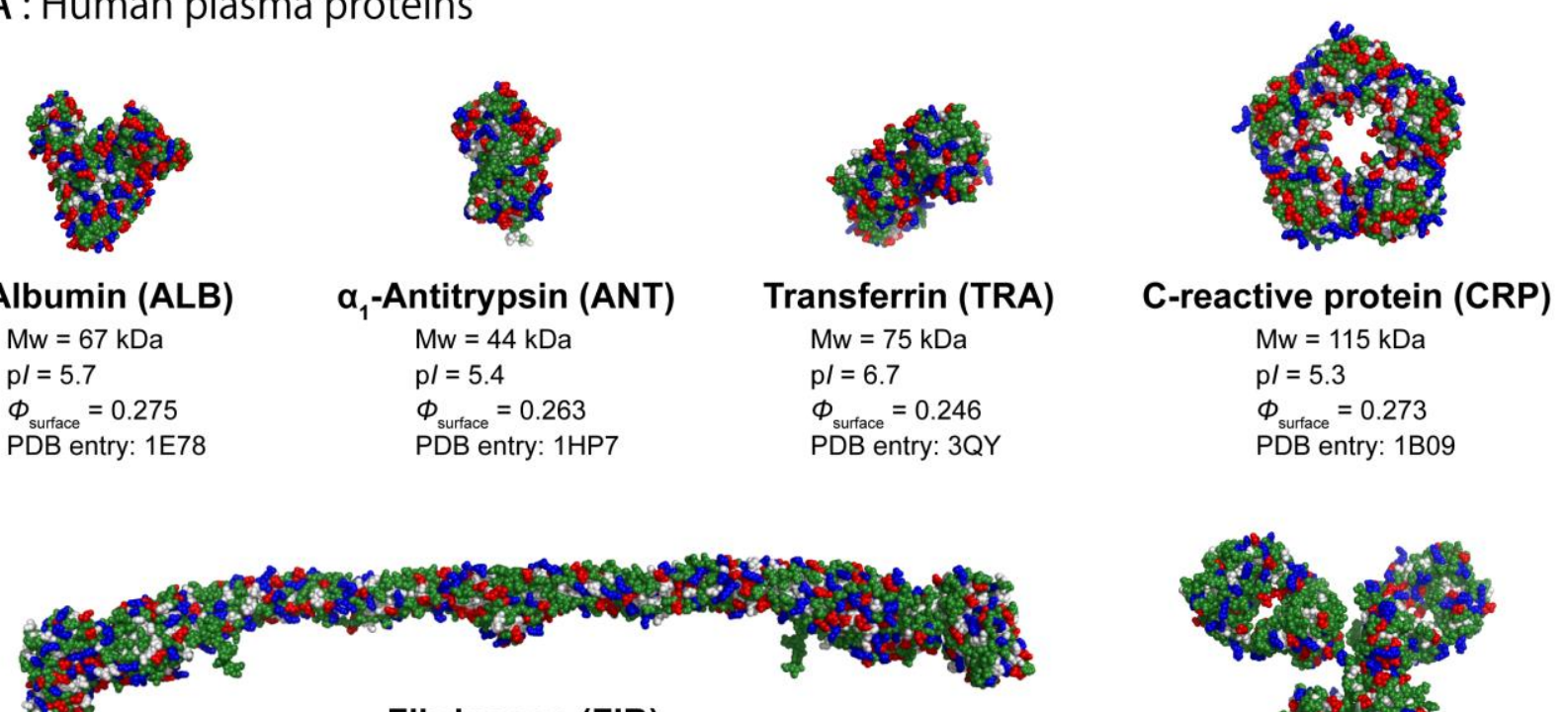

Fibrinogen (FIB)

$\mathrm{Mw}=387 \mathrm{kDa}$

$\mathrm{p} /=5.7$

$\Phi_{\text {surace }}=0.289$

PDB entry: $3 G H G$

Immunoglobulin G (IMM)

$\mathrm{Mw}=143 \mathrm{kDa}$

$\mathrm{p} /=7.3$

$\Phi_{\text {surface }}=0.273$

PDB entry: 1IGY

B : Mammalian sera

\begin{tabular}{lcccccc}
\hline Sources & $\begin{array}{c}\text { Total protein, } \\
\mathrm{mg} / \mathrm{mL}\end{array}$ & $\begin{array}{c}\text { Albumin, } \\
\%\end{array}$ & $\begin{array}{c}\alpha \text { 1-globulins, } \\
\%\end{array}$ & $\begin{array}{c}\alpha 2-\text { globulins, } \\
\%\end{array}$ & $\begin{array}{c}\beta \text {-globulins, } \\
\%\end{array}$ & $\begin{array}{c}\text { Y-globulins, } \\
\%\end{array}$ \\
\hline Horse $^{1}$ & 61.5 & 55.9 & 4.2 & 11.3 & 14.4 & 14.2 \\
Rabbit $^{2}$ & 66.1 & 59.1 & 2.3 & 7.3 & 14.5 & 16.6 \\
Bovine $^{3}$ & 63.8 & 63.3 & 4.9 & 7.5 & 12.7 & 11.6 \\
Fetal bovine $^{3}$ & 61.8 & 61.9 & 4.7 & 8.0 & 9.7 & 15.7 \\
Human $^{4}$ & 72.9 & 53.3 & 8.0 & 10.4 & 13.8 & 14.2 \\
\hline
\end{tabular}

C: Mammalian cells

\begin{tabular}{lcc}
\hline Cell type & Name & Source \\
\hline Cancer cell line & A549 & Lung \\
& MG63 & Bone \\
& HuH7 & Liver \\
Mesenchymal stem cell line & UE7T-13 & Bone marrow \\
\hline
\end{tabular}

Figure S-1. Profiles of biological analytes used in this study. (A) Human plasma proteins. p $I$ values of proteins were calculated theoretically taking into account the amino acid compositions of proteins and the $\mathrm{p} K$ values of the side chains. $\Phi_{\text {surface }}$ values of proteins were calculated based on the Miyazawa-Jernigan hydrophobicity scale was estimated using the previously described method $^{5}$ with the accessible surface areas of proteins calculated using the program GETAREA. ${ }^{6}$ (B) Mammalian sera. Total protein concentration and protein fractions for mammalian sera are shown. The values for fetal bovine serum were obtained from the supplier. (C) Mammalian cells. 


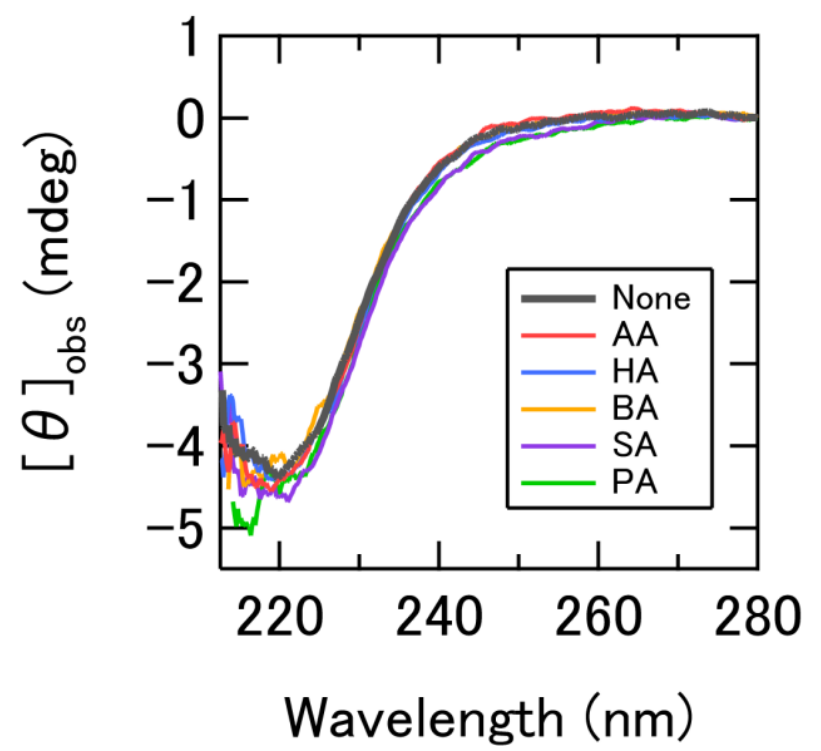

Figure S-2. Far-UV CD spectra of unmodified $\beta$-Gal (E1) mixed with hydrolyzed acetic anhydride (AA), hexanoic anhydride (HA), benzoic anhydride (BA), succinic anhydride (SA) and phthalic anhydride (PA). 

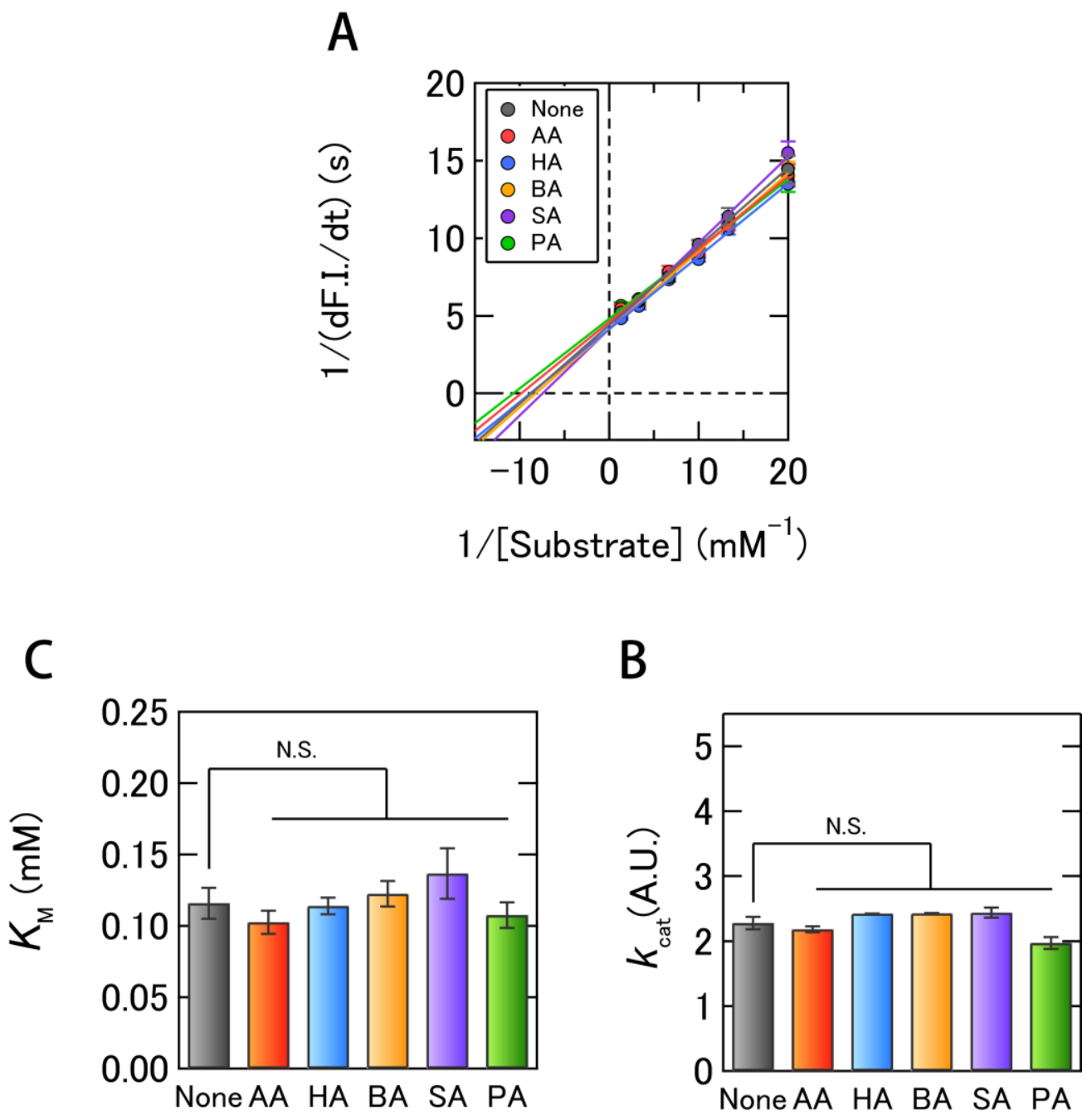

Figure S-3. Kinetic experiments of unmodified $\beta$-Gal mixed with hydrolyzed acid hydrides. (A) Lineweaver-Burk plot for substrate hydrolysis by the unmodified $\beta$-Gal (E1) mixed with hydrolyzed acetic anhydride (AA), hexanoic anhydride (HA), benzoic anhydride (BA), succinic anhydride (SA), and phthalic anhydride (PA). Values represent the means \pm S.E. $(n=3)$. (B) The Michaelis constant $\left(K_{\mathrm{M}}\right)$ and $(\mathrm{C})$ the turnover number $\left(k_{\mathrm{cat}}\right)$ of E1 mixed with hydrolyzed acid anhydrides. Values represent the means \pm S.E. ( $n=3$, N.S., not significant against $\mathbf{E 1}$ alone). 


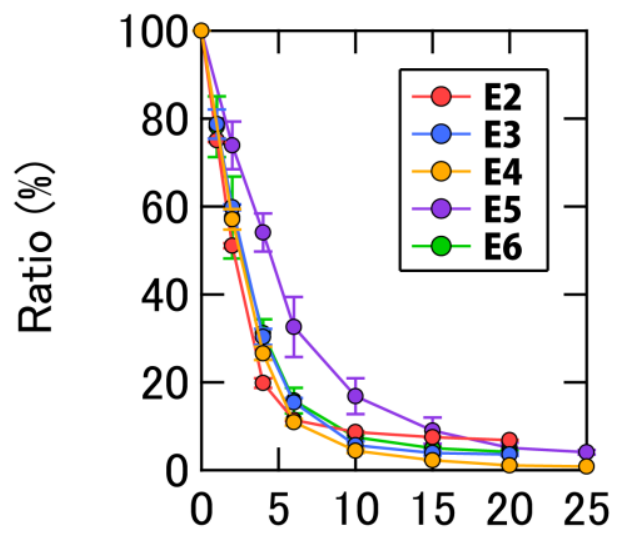

[Acid anhydride]/[- $\left.\mathrm{NH}_{3}^{+}\right]$

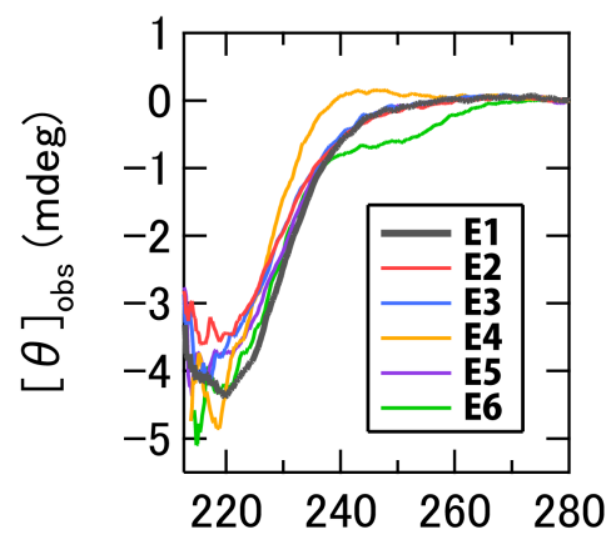

Wavelength $(\mathrm{nm})$

Figure S-4. Preparation and characterization of $\beta$-Gals modified with various acid anhydrides. (A) Ratio of the fluorescence before and after mixing $\beta-G a l$ with various concentrations of acid anhydrides. Values are shown as means \pm S.E. $(n=3)$. (B) Far-UV CD spectra of artificially modified $\beta$-Gals.
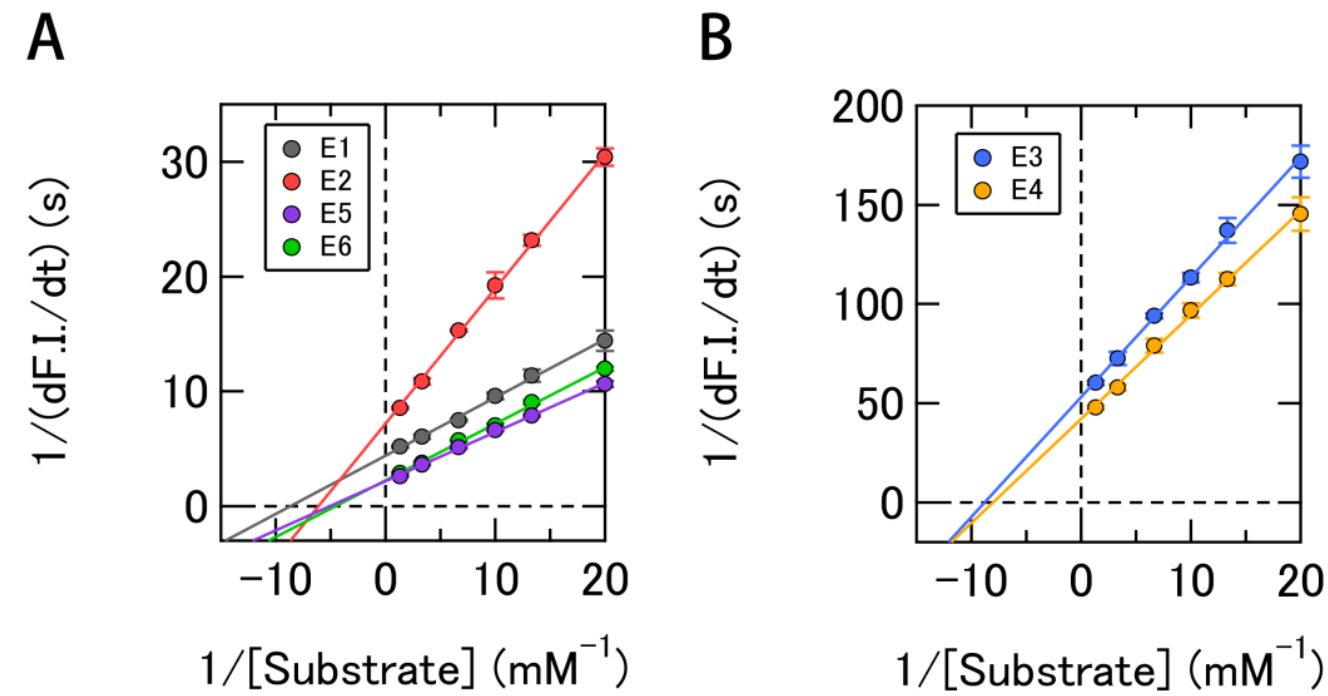

Figure S-5. Lineweaver-Burk plots for substrate hydrolysis by (A) E1, E2, E5, and E6 and (B) E3 and E4. Values represent the means \pm S.E. $(n=3)$. 


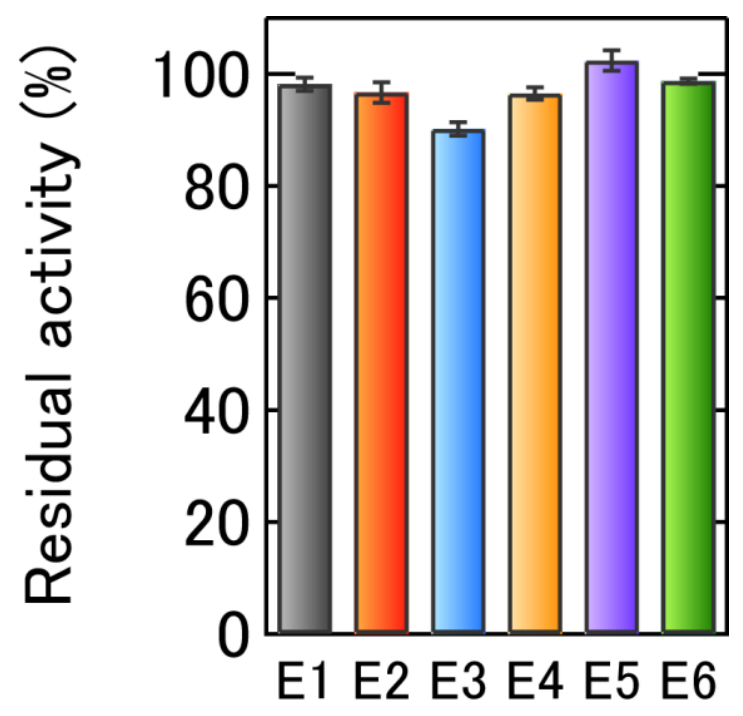

Figure S-6. Residual activities of artificially modified $\beta$-Gals after shaking treatment at $2000 \mathrm{rpm}$ for 30 minutes at room temperature. 


\begin{tabular}{|c|c|c|c|c|c|c|c|c|c|c|c|c|c|c|c|}
\hline \multicolumn{7}{|c|}{ Selected GAOs } & & \multicolumn{8}{|c|}{ \%correct } \\
\hline & E1 & E2 & E3 & E4 & E5 & E6 & $0.3 \mathrm{CRP}$ & $0.3 \mathrm{FIB}$ & $0.9 \mathrm{CRP}$ & $0.9 \mathrm{FIB}$ & $2.7 \mathrm{CRP}$ & $2.7 \mathrm{FIB}$ & $8.1 \mathrm{CRP}$ & $8.1 \mathrm{FIB}$ & Total \\
\hline 2PICs & & & & & & & 100 & 100 & 100 & 50 & 100 & 67 & 67 & 67 & 81 \\
\hline \multirow[t]{4}{*}{ 3PICs } & & & & & & & 100 & 100 & 100 & 100 & 100 & 100 & 100 & 100 & 100 \\
\hline & & & & & & & 83 & 83 & 67 & 50 & 100 & 83 & 100 & 100 & 83 \\
\hline & & & & & & & 100 & 83 & 100 & 83 & 100 & 83 & 67 & 100 & 90 \\
\hline & & & & & & & 100 & 83 & 100 & 50 & 100 & 67 & 67 & 67 & 79 \\
\hline \multirow[t]{3}{*}{ 4PICs } & & & & & & & 100 & 100 & 100 & 100 & 100 & 100 & 100 & 100 & 100 \\
\hline & & & & & & & 100 & 100 & 100 & 100 & 100 & 100 & 100 & 83 & 97 \\
\hline & & & & & & & 100 & 83 & 100 & 83 & 100 & 83 & 67 & 83 & 88 \\
\hline 5PICs & & & & & & & 100 & 100 & 100 & 100 & 100 & 100 & 100 & 100 & 100 \\
\hline
\end{tabular}

$$
\begin{array}{l|l} 
& \begin{array}{l}
\text { Selected } 3 \text { combinations } \\
\text { [P1/E1, P1/E2, P1/E6】 }
\end{array} \\
\text { B } & \text { [P1/E1, P1/E2, P1/E3, P1/E5】 } \\
\text { [P1/E1, P1/E2, P1/E3, P1/E4, P1/E5】 }
\end{array}
$$

\begin{tabular}{|c|c|c|c|c|c|c|c|c|c|c|c|c|}
\hline & \multicolumn{6}{|c|}{ Selected GAOs } & \multicolumn{6}{|c|}{ \%correct } \\
\hline & E1 & E2 & E3 & E4 & E5 & E6 & Bovine & Fetal bovine & Horse & Human & Rabbit & Total \\
\hline 3PICs & & & & & & & 100 & 100 & 100 & 100 & 100 & 100 \\
\hline 4PICs & & & & & & & 100 & 100 & 100 & 100 & 67 & 93 \\
\hline $5 \mathrm{PICs}$ & & & & & & & 100 & 100 & 100 & 83 & 67 & 90 \\
\hline
\end{tabular}

Selected 1 combination

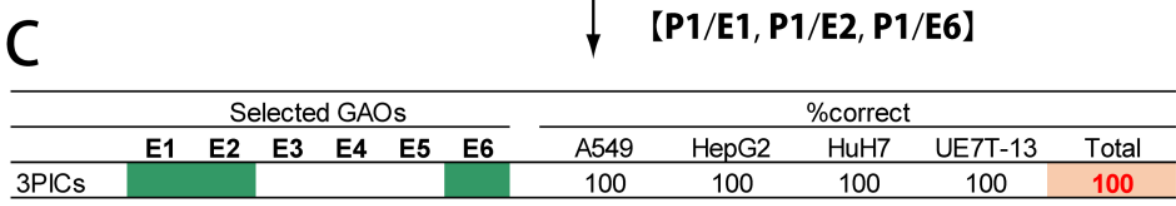

Figure S-7. Schematic representation of the process for exploring the best combination of PICs based on the Jackknife classification procedure. (A) Classification accuracy for FIB and CRP with different concentrations. Ten combinations providing 100\% accuracy for discrimination of plasma proteins (see Table S2) were selected for the analyses. The same process was repeated for (B) mammalian sera and (C) cells. 
A

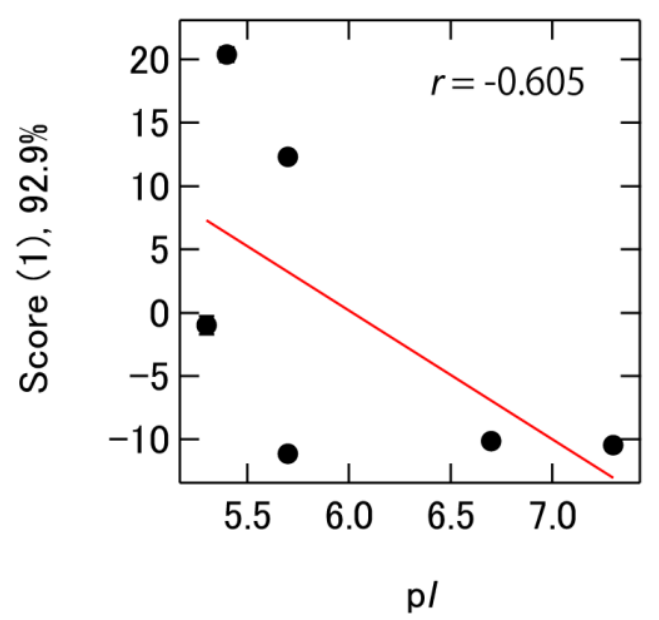

B

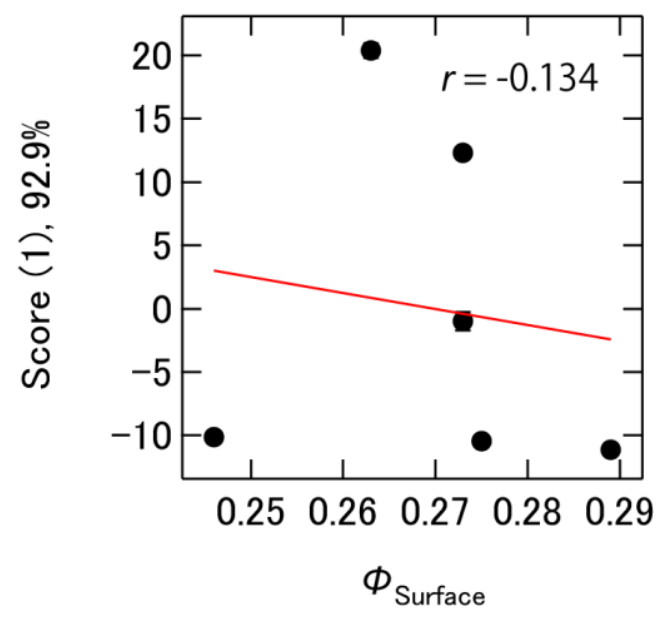

Figure S-8. First discriminant scores shown in Figure 4B vs. (A) p $I$ and (B) $\Phi_{\text {surface }}$ values of plasma proteins. 
A

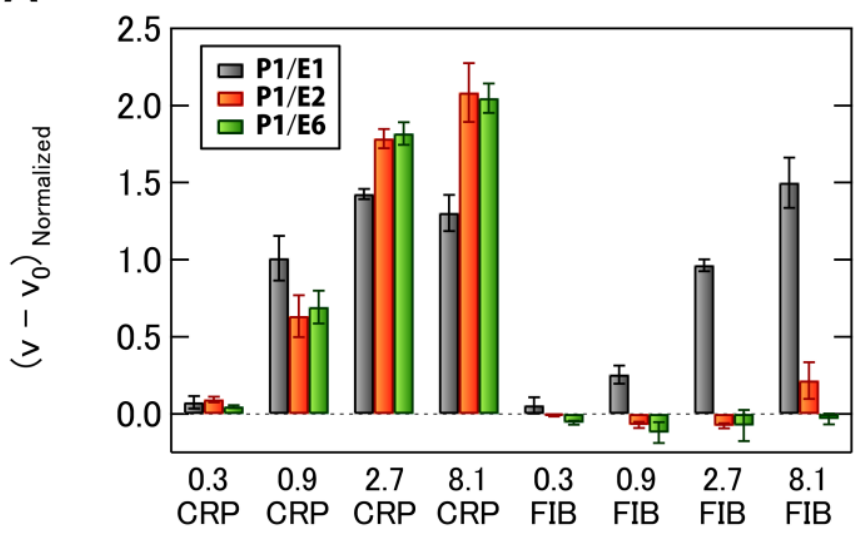

B
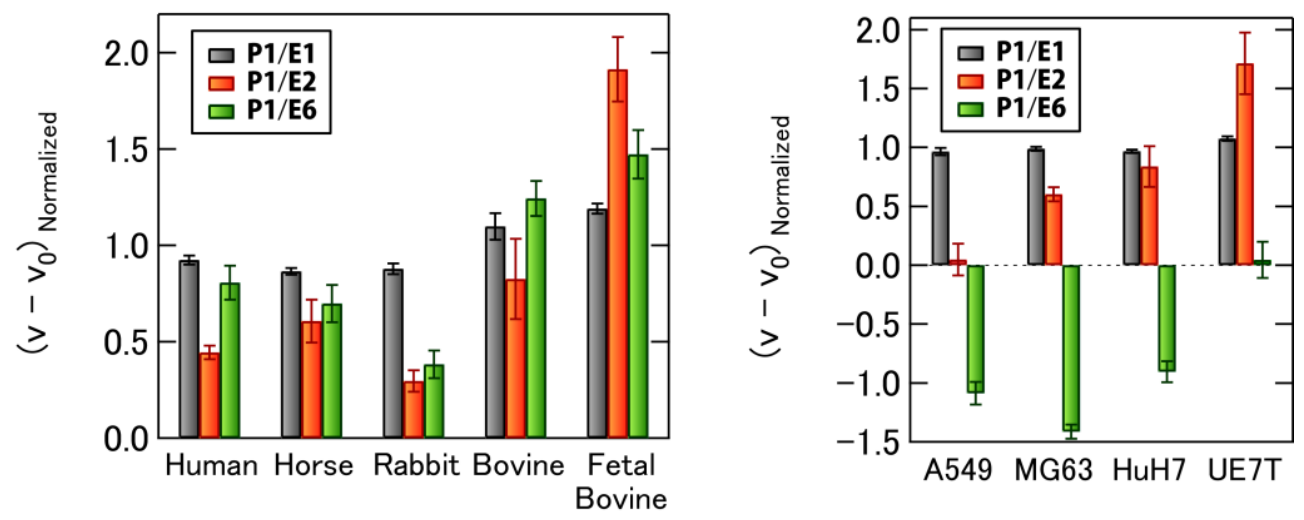

Figure S-9. Fingerprints of changes in enzyme activity for different concentrations of inflammatory biomarker proteins, mammalian sera and cells. Fingerprints of changes in enzyme activity for (A) FIB and CRP in different concentrations, (B) mammalian sera, and (C) cells obtained using three PICs (P1/E1, P1/E2, and P1/E6). Values represent the means \pm S.D. $(n=6)$. The values were divided by the root mean square of the corresponding PIC data to facilitate visual comparison between each of the PIC results. 
B
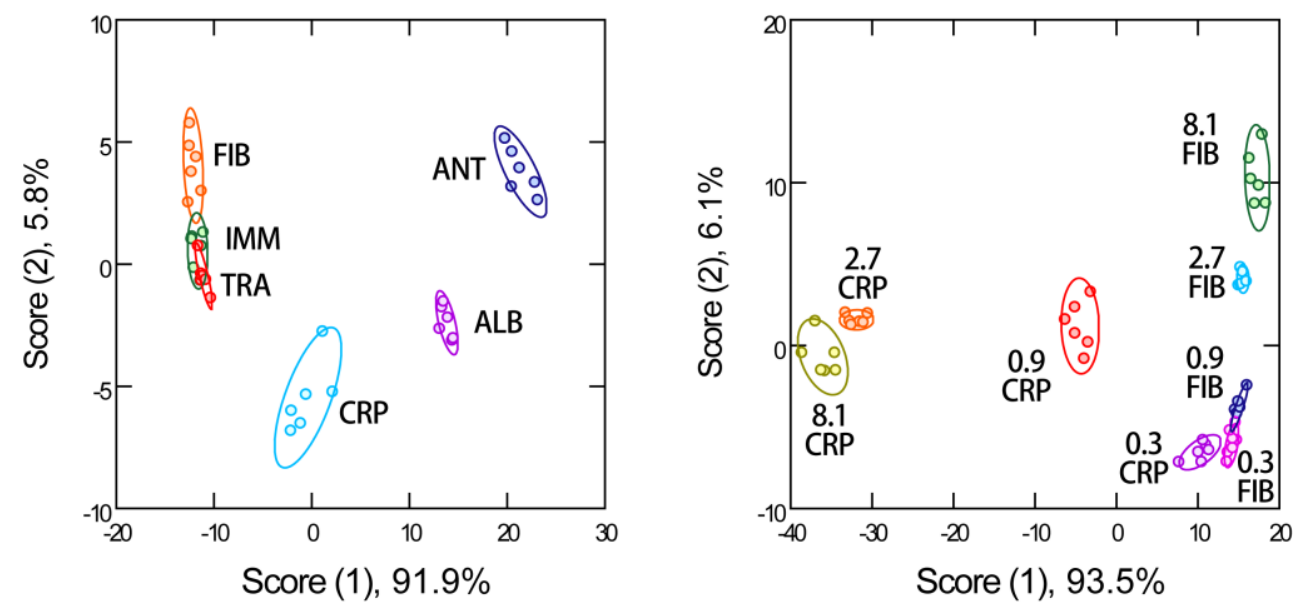

C

D
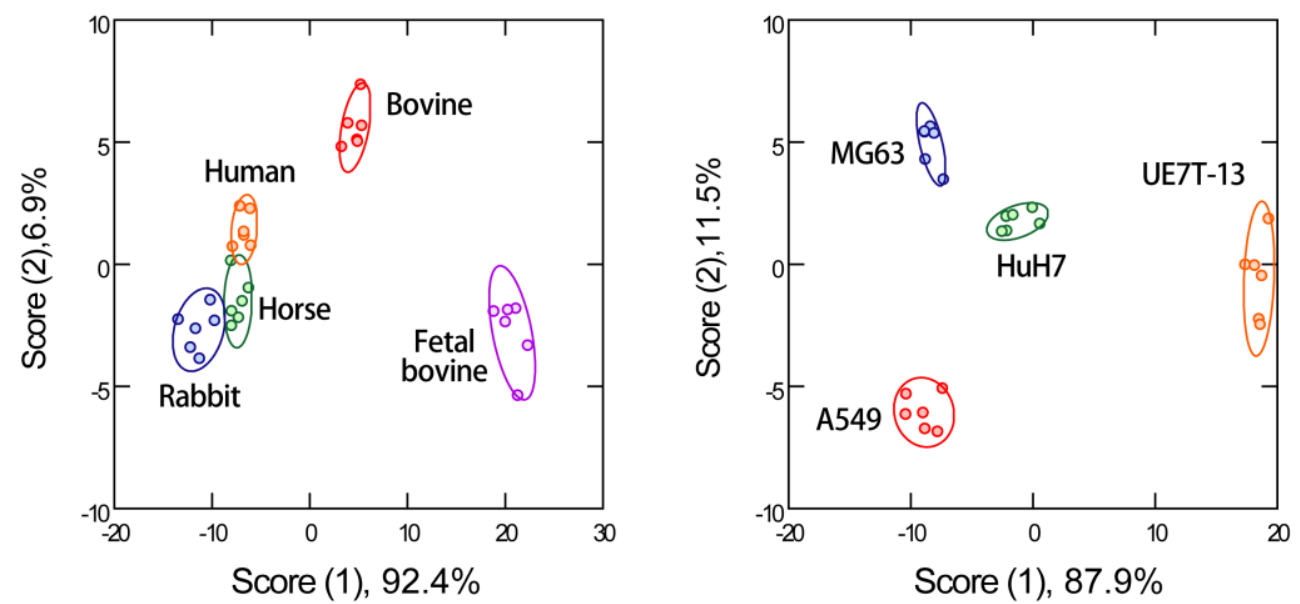

Figure S-10. Discriminant score plot for (A) $0.5 \mu \mathrm{g} / \mathrm{mL}$ human plasma proteins, (B) the quantitative response of FIB and CRP $(0.3-8.1 \mu \mathrm{g} / \mathrm{mL})$, (C) mammalian sera containing $2.5 \mu \mathrm{g} / \mathrm{mL}$ serum proteins, and (D) 1500 cells/mL mammalian cells using six PICs (P1/E1, P1/E2, P1/E3, P1/E4, P1/E5 and P1/E6). The ellipses represent confidence intervals ( \pm 1 S.D.) for the individual analytes. 

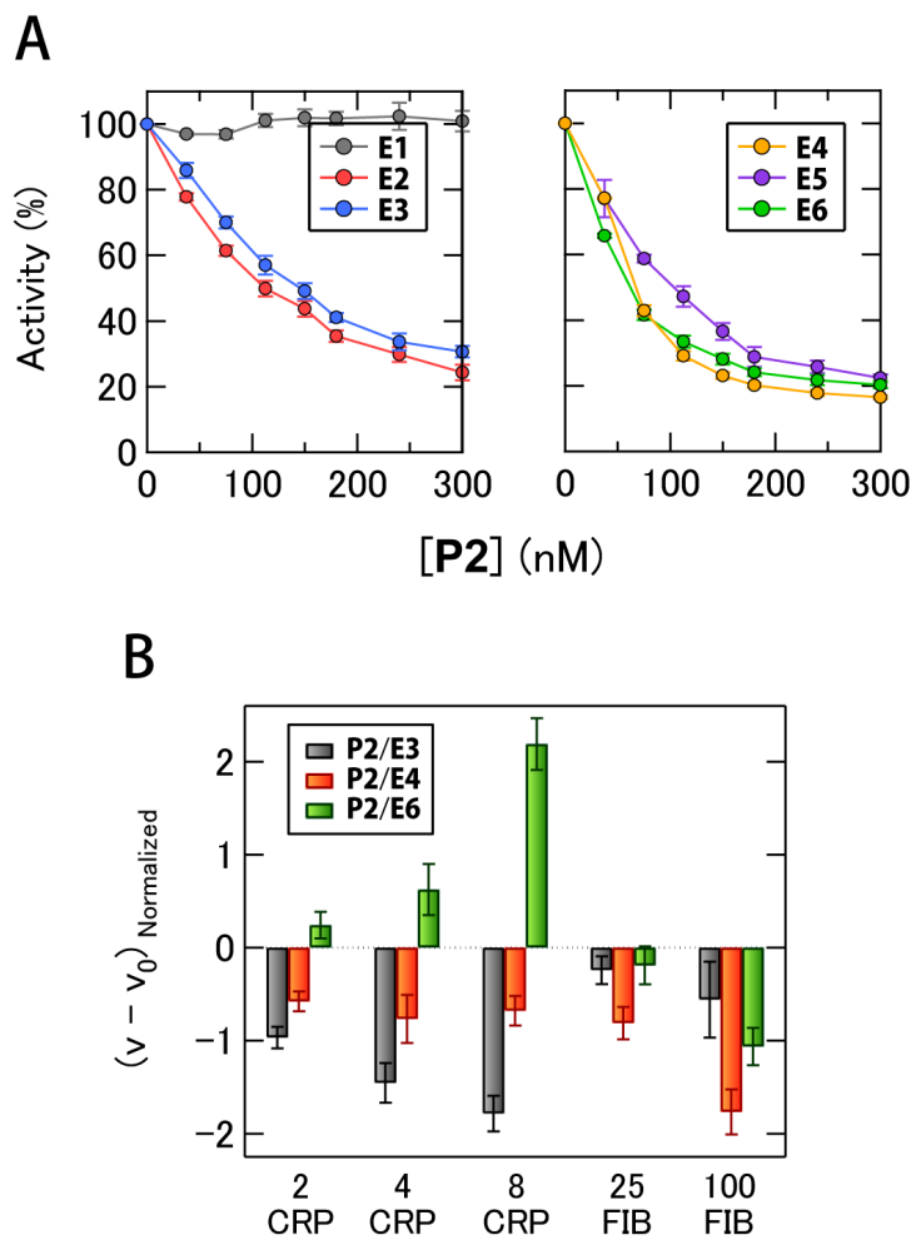

Figure S-11. (A) Normalized activities of artificially modified $\beta$-Gals in the presence of P2. Various concentrations of $\mathbf{P 2}$ were added to solutions containing 1.0 nM $\beta$-Gals in $10 \mathrm{mM}$ MOPS (pH 7.0) with $1 \%$ human serum. Values are shown as means \pm S.E. $(n=3)$. (B) Fingerprints of changes in enzyme activity for FIB and CRP in different concentrations in $10 \mathrm{mM}$ MOPS (pH 7.0) with $1 \%$ human serum obtained using three PICs $(\mathbf{P 2} / \mathbf{E 3}, \mathbf{P 2} / \mathbf{E 4}$, and P2/E6). Values represent the means \pm S.D. $(n=6)$. The values were divided by the root mean square of the corresponding PIC data. 


\section{References}

(1) Riond, B.; Wenger-Riggenbach, B.; Hofmann-Lehmann, R.; Lutz, H. Vet. Clin. Pathol. 2009, 38, 73.

(2) Rupic, V.; Muzic, S.; Stipic, N.; Skrlin, J.; Bacar-Huskic, L. Acta. Vet. Brno. 1999, 68, 91.

(3) Longsworth, L.G.; Curtis, R.M.; Pembroke, R.H. J. Clin. Invest. 1945, 24, 46.

(4) Seibert, F.B.; Seibert, M.V.; Atno, A.J.; Campbell, H.W. J. Clin. Invest. 1947, 26, 90.

(5) Lienqueo, M.E.; Mahn, A.; Asenjo, J.A. J. Chromatogr. A. 2002, 978, 71.

(6) Fraczkiewicz, R.; Braun, W. J. Comput. Chem. 1998, 19, 319. 